\title{
Parto humanizado: uma revisão integrativa
}

\author{
Humanized childbirth: an integrative review \\ Parto humanizado: una revisión integradora
}

Recebido: 15/11/2021 | Revisado: 24/11/2021 | Aceito: 25/11/2021 | Publicado: 07/12/2021

\author{
Amanda Oliveira Souza \\ ORCID: https://orcid.org/0000-0001-5323-3631 \\ Universidade Paulista, Brasil \\ E-mail: amandinhasz.22@gmail.com \\ Viviane Duarte Chicarino \\ ORCID: https://orcid.org/0000-0003-3200-3866 \\ Universidade Paulista, Brasil \\ Andrey Hudson Interaminense Mendes de Araújo \\ ORCID: https://orcid.org/0000-0003-4718-5084 \\ Universidade Paulista, Brasil \\ E-mail: andrey.araujo@docente.unip.br
}

\begin{abstract}
Resumo
Objetivo: Avaliar e identificar as principais dificuldades encontradas durante o atendimento a parturientes e apresentar metodologias de educação continuada. Métodos: Estudo de revisão integrativa, buscando analisar estudos científicos acerca da percepção da enfermagem no atendimento humanizado. Resultados: Criado um quadro síntese contendo 23 artigos para serem analisados; 09 deles analisou-se a importância em preparar a mulher desde o início da gestação. 03 com objetivo de avaliar o conhecimento dos enfermeiros técnico e científico adequado para a assistência. 05 no que se refere a vincular conhecimento, melhorar a qualidade da assistência humanizada pela equipe de enfermagem incluindo a mulher. 06 como sugestão de educação continuada e capacitação profissional. Conclusão: para minimizar os erros cometidos durante a atuação e garantir o sucesso de uma assistência qualificada da equipe, depende de diversos fatores individuais e coletivos. O enfermeiro como gestor principal de cada unidade, deve ter a preocupação de instaurar educação continuada para sua equipe, implementar protocolos de assistência ao cuidado humanizado, e realizar o papel de fiscalizador contínuo.
\end{abstract}

Palavras-chave: Humanização da assistência; Parto humanizado; Cuidados de enfermagem; Obstetrícia.

\begin{abstract}
Objective: Assess and identify the main difficulties encountered during care delivery to parturients and present continuing education methodologies. Methods: Integrative review study, seeking to analyze scientific studies on the perception of nursing in humanized care. Results: Created a summary table containing 23 articles to be analyzed; 09 of them analyzed the importance of preparing the woman from the beginning of pregnancy. 03 in order to assess the knowledge of technical and scientific nurses adequate for care. 05 with regard to linking knowledge, improve the quality of humanized care by the nursing team, including women. 06 As a suggestion for continuing education and professional training. Conclusion: to minimize the mistakes made during the performance and ensure the success of qualified assistance from the team, it depends on several individual and collective factors. The nurse, as the main manager of each unit, must be concerned with establishing continuing education for their team, implementing assistance protocols for humanized care, and performing the role of continuous supervisor.
\end{abstract}

Keywords: Humanization of care; Humanized childbirth; Nursing care; Obstetrics.

\section{Resumen}

Objetivo: Evaluar e identificar las principales dificultades encontradas durante la atención a partos y presentar metodologías de educación continuada. Métodos: Estudo de revisão integrativa, procurando analisar estudos científicos sobre a percepção da enfermagem no atendimento humanizado. Resultados: Creó un cuadro de síntesis que contiene 23 artículos para ser analizados; 09 de ellos analizan la importancia en la preparación de la mujer desde el inicio del embarazo. 03 con el objetivo de evaluar los conocimientos técnicos y científicos de las enfermeras adecuados para la asistencia. 05 en cuanto a la vinculación de conocimientos, mejorar la calidad de la asistencia humanizada por el equipo de enfermería incluyendo a la mujer. 06 como sugerencia para la formación continua y la capacitación profesional. Conclusión: minimizar los errores cometidos durante la actuación y garantizar el éxito de una asistencia cualificada del equipo, depende de varios factores individuales y colectivos. El enfermero, como gestor principal de cada unidad, debe tener la preocupación de instaurar la educación continuada para su equipo, implementar protocolos de asistencia al cuidado humanizado, y realizar el papel de fiscalizador contínuo.

Palavras-chave: Humanización de la asistencia; Parto humanizado; Cuidados de enfermería; Obstetricia. 


\section{Introdução}

A humanização do parto é uma das ações que integram a Política Nacional da Humanização (PNH) cujo argumento é o atendimento humanizado às usuárias do Sistema Único de Saúde (SUS). Os gestores da saúde têm o dever de proporcionar melhores condições para implementar um modelo de assistência que tenha a inclusão do enfermeiro obstetra para participar da assistência ao parto de baixo risco, por ter conhecimento técnico científico para auxiliar a parturiente durante o processo do parto, por ter condições de apresentar vantagens reduzindo as intervenções e propiciando satisfação das mesmas. A implementação desse modelo assistencial incluindo a obstetrícia é um desafio requerendo muito esforço da parte dos gestores quanto dos profissionais de saúde, pois essa implementação gera custos (Bonfim, et al, 2021).

Por muito tempo, os únicos tipos de parto eram: o normal e a cesariana, e os dois são muito diferentes: enquanto no parto normal o bebê nasce pelo canal vaginal, e a cesariana exige uma cirurgia propriamente dita, com a extração do bebê diretamente do útero (Costa, \& Dalla, 2021). No geral o parto cesariano é recomendado apenas em casos de risco ou emergência, com o parto normal sendo recomendada como primeira escolha, pela Organização Mundial da Saúde (OMS) devido aos diversos benefícios e à diminuição dos riscos maternos e neonatais (Spigolon, et al, 2020).

A (OMS), bem como o Ministério da Saúde (MS) determinam algumas diretrizes para o parto normal, que deve ser acompanhada por um profissional médico que conhece o planejamento da gestante e de sua família, além do seu histórico de saúde, o bem-estar físico e mental da mulher, que é essencial antes, durante e depois de dar à luz (Vidal, et al, 2021).

Porém o parto normal, no sistema de saúde brasileiro vem sendo permeado de procedimentos invasivos que muitas vezes são realizados sem o consentimento da parturiente. Um exemplo claro é o uso de fármacos para estimular o nascimento ou para evitar a dor, por mais que pareça positivo, é necessário ter o consentimento e aceitação da paciente antes da administração, mas na realidade nem sempre acontece (Silva, et al, 2016).

Outros procedimentos comuns que são ineficazes e até mesmo prejudiciais são: a tricotomia total na região pubiana, a lavagem intestinal, infusões intravenosas, uso da posição ginecológica (deitada com as pernas levantadas em apoios), distensão de períneo e até mesmo a lavagem do útero após o parto (Vidal, et al, 2021). Nesse cenário, o parto normal se distancia do que deveria ser a forma mais natural de parir, com uso de remédios e técnicas de indução para apressar o parto, o tempo da mãe com o bebê acaba não sendo respeitado (Silva, et al, 2016). Foi para resolver essas questões que surgiu o parto humanizado (Spigolon, et al, 2020).

Dentre as atividades de enfermagem descritas na resolução Conselho Federal de Enfermagem (COFEN) № 524/2016, compete ao enfermeiro obstetra o acolhimento da mulher e seus familiares, avaliação das condições de saúde materna e fetais, realização de consultas de enfermagem, promoção do modelo de assistência centrado na mulher, adoção de práticas baseadas em evidências científicas, garantia de integralidade do cuidado à mulher, avaliação da evolução do trabalho de parto, entre outros (Domingues, et al, 2015).

Assim, uma atuação profissional qualificada que respeite os aspectos da fisiologia do trabalho de parto, dando autonomia à mulher durante todo o processo, e que não intervenha desnecessariamente, e que informe sobre todos os procedimentos que serão realizados é a melhor estratégia a ser adotada, garantindo assim os direitos de cidadania (Almeida, et al, 2021) (Costa, et al, 2021). Nesse sentido é necessário que o profissional esteja apto para interagir com esses cuidados (Leal, et al, 2021).

O presente estudo tem como pergunta norteadora: Qual o conhecimento do enfermeiro sobre a necessidade do uso de intervenções durante o parto? O objetivo foi avaliar através de estudos científicos o conhecimento dos enfermeiros nos cuidados relacionados às parturientes no ambiente intra-hospitalar, tendo como base a assistência humanizada. Além disso, identificar as principais dificuldades da enfermagem encontradas durante o atendimento à pacientes em trabalho de parto $\mathrm{e}$ apresentar metodologias de educação continuada. 


\section{Métodos}

Trata-se de um estudo de revisão integrativa da literatura, propondo e estabelecendo critérios definidos referentes à coleta de dados, análise e apresentação dos resultados. Foram utilizadas as seguintes etapas: 1) identificação do tema e seleção da hipótese ou questão de pesquisa para a elaboração da revisão integrativa; 2) estabelecimento de critérios para inclusão e exclusão de estudos; 3) definição das informações a extrair dos estudos selecionados; 4) avaliação dos estudos incluídos na revisão integrativa; 5) interpretação dos resultados; e 6) apresentação da revisão.

Na estratégia de busca, foram consultados na Biblioteca Virtual da Saúde (BVS) por meio das bases de dados: Base de dados bibliográficas especializada na área de Enfermagem (BDENF), Sistema Online de Busca e Análise de Literatura Médica (MEDLINE), Literatura Latino-americana e do Caribe em Ciências da Saúde (LILACS) e Biblioteca Eletrônica Científica Online (SCIELO).

Na Sistematização das buscas utilizou o operador booleano AND, e registros nos descritores em ciência na saúde DECs: "humanização da assistência", "parto humanizado", "cuidados de enfermagem", e "obstetrícia". Ao qual foram encontrados 5.639 artigos, dos quais após a utilização de filtros, utilizou-se como critérios de inclusão: artigos originais, idioma Português e períodos de 2015 a 2021 que abordassem o tema humanização da assistência a gestante, e que tenham relação com o objetivo desse trabalho. Os critérios de exclusão foram: artigos de revisão da literatura integrativa, publicações anteriores a 2015, artigos em outros idiomas, e aqueles que não estavam relacionados ao tema proposto. Após selecionar os filtros ficaram apenas 305 artigos na BVS, e após leitura minuciosa dos títulos e resumos foram selecionados 23 artigos para compor este estudo. Os artigos selecionados foram lidos na íntegra, a fim de determinar as informações de maior interesse para a pesquisa. A coleta de dados foi realizada entre o período de agosto/2021 a novembro/2021.

A metodologia utilizada fundamentou-se na análise de conteúdo de (Bonfim, Couto, Lima, Almeida, Santo, \& Santana, 2021) que sugere que os profissionais tenham acesso à educação continuada e comprometimento em relação a constituir alicerces para a humanização do parto.

Figura 1: Fluxograma de seleção de artigos: Busca na BVS utilizando descritores ("humanização da assistência", "parto humanizado", "cuidados de enfermagem", e "obstetrícia").

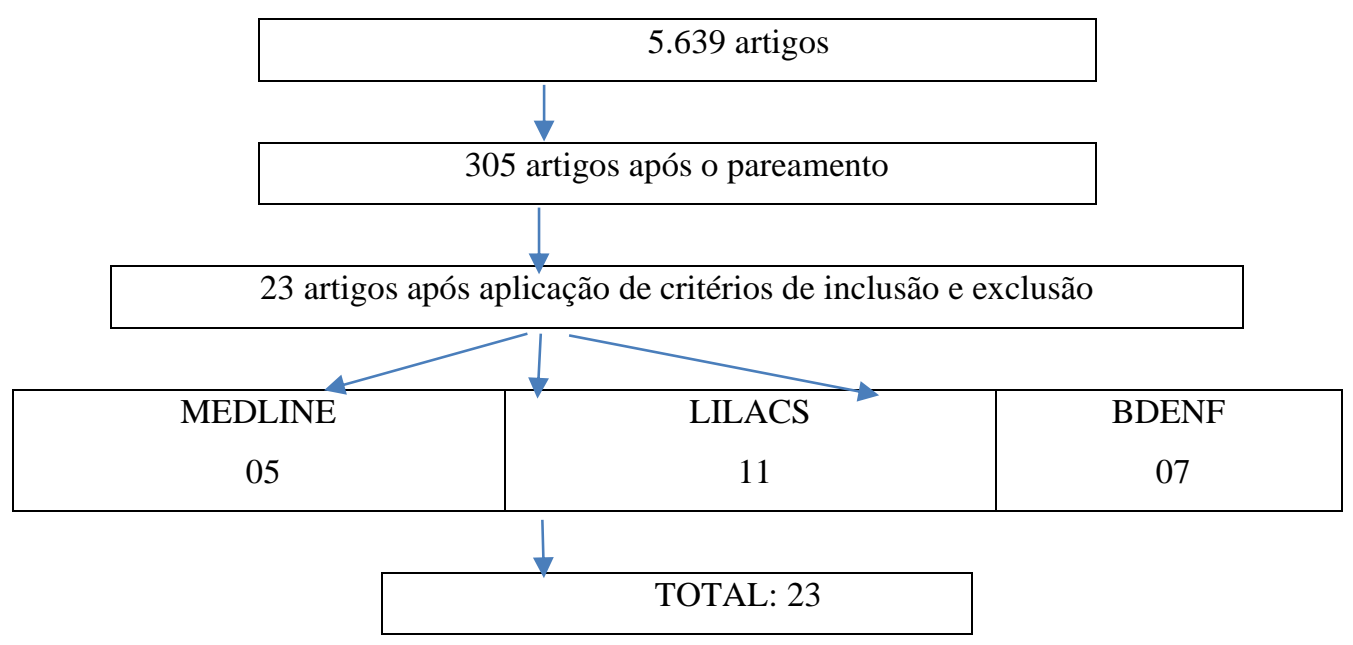

Fonte: Dados da pesquisa. 


\section{Resultados}

Após a leitura dos artigos, construiu-se uma tabela referenciando título, autores objetivo, método, conclusão e ano de publicação. Foi sistematizado um quadro síntese contendo 23 artigos selecionados para serem analisados no presente estudo (fig. 2). Dentre os artigos incluídos na revisão, 02 foram publicados no ano de 2015, 01 no ano de 2016, 03 foram publicados no ano de 2017, 05 no ano de 2018, 02 no ano de 2019, 04 no ano de 2020 e 06 em 2021. Desta forma, os objetivos e os resultados encontrados neste estudo contribuirão para aprofundamento do tema estudado, proporcionando ao enfermeiro o conhecimento científico inerente ao tema proposto.

Figura 2: Distribuição dos artigos de acordo com: título, autores, objetivo, método, conclusão e ano de publicação.

\begin{tabular}{|c|c|c|c|c|c|c|}
\hline & Título & Autor & Objetivo & Método & Conclusão & Ano \\
\hline$\overbrace{\substack{1 \\
2}}^{\infty}$ & $\begin{array}{l}\text { Parir e nascer em casa: } \\
\text { vivências de enfermeiras } \\
\text { obstétricas na assistência } \\
\text { ao parto domiciliar } \\
\text { planejado. }\end{array}$ & $\begin{array}{l}\text { Almeida, } \\
\text { A.I.S; } \\
\text { Araújo F, } \\
\text { Luzia C }\end{array}$ & $\begin{array}{lc}\text { Discutir a vivência de } \\
\text { enfermeiras que atuam na } \\
\text { assistência ao parto } \\
\text { domiciliar } & \text { planejado, } \\
\text { evidenciando } & \text { práticas } \\
\text { obstétricas, desafios e } \\
\text { obstáculos. }\end{array}$ & $\begin{array}{l}\text { Estudo qualitativo, } \\
\text { realizado no período de } \\
\text { agosto de } 2019 \text { a março de } \\
2020, \text { com nove } \\
\text { enfermeiras obstétricas } \\
\text { atuantes no cenário de } \\
\text { parto domiciliar. }\end{array}$ & $\begin{array}{l}\text { Constatou-se que a enfermagem } \\
\text { obstétrica no parto domiciliar } \\
\text { planejado se apresenta como uma } \\
\text { opção para o resgate do parto } \\
\text { fisiológico. }\end{array}$ & 2021 \\
\hline$\overbrace{\substack{1 \\
\hdashline}}^{2}$ & $\begin{array}{l}\text { Percepções de mulheres } \\
\text { sobre a assistência de } \\
\text { Enfermagem durante o } \\
\text { parto normal. }\end{array}$ & $\begin{array}{l}\text { Bonfim } \\
\text { A.N.A, } \\
\text { Couto T.M, } \\
\text { Lima } \\
\text { K.T.R.S, et } \\
\text { al. }\end{array}$ & $\begin{array}{l}\text { Conhecer a percepção das } \\
\text { parturientes referente a } \\
\text { assistência de Enfermagem } \\
\text { recebida durante o } \\
\text { processo de parto normal. }\end{array}$ & $\begin{array}{l}\text { Pesquisa descritiva com } \\
\text { abordagem qualitativa, } \\
\text { efetuada em duas } \\
\text { maternidades públicas de } \\
\text { Salvador, Bahia, Brasil. }\end{array}$ & $\begin{array}{l}\text { Sugere educação continuada e } \\
\text { comprometimento } \\
\text { profissionais do de } \\
\text { constituindo alicerces para a } \\
\text { humanização do parto. }\end{array}$ & 2021 \\
\hline$\overbrace{\substack{\infty \\
+\infty}}^{n}$ & $\begin{array}{l}\text { Adesão de profissionais } \\
\text { às boas práticas } \\
\text { obstétricas r } \\
\text { intervenções realizadas } \\
\text { com parturientes. }\end{array}$ & $\begin{array}{l}\text { Costa, LD. } \\
\text { et al. }\end{array}$ & $\begin{array}{l}\text { Analisar a associação entre } \\
\text { as boas práticas obstétricas } \\
\text { e os tipos de parto. }\end{array}$ & $\begin{array}{lr}\text { Estudo transversal, } \\
\text { realizado com } 207 \\
\text { parturientes internadas em } \\
\text { duas maternidades de } \\
\text { referência, cujos dados } \\
\text { foram coletados por } \\
\text { questionário e análise do } \\
\text { prontuário e analisados } \\
\text { pelo teste Qui-quadrado de } \\
\text { Pearson. }\end{array}$ & $\begin{array}{l}\text { Observou-se que as boas práticas } \\
\text { obstétricas estavam associadas à } \\
\text { via de parto normal, enquanto, no } \\
\text { parto cesárea, tais práticas foram } \\
\text { implementadas com menos } \\
\text { frequência. }\end{array}$ & 2021 \\
\hline$\frac{\pi}{2}$ & $\begin{array}{l}\text { Práticas de humanização } \\
\text { no transcurso parturitivo } \\
\text { na ótica de puérperas e } \\
\text { enfermeiras obstétricas. }\end{array}$ & $\begin{array}{l}\text { Leal M.S, } \\
\text { Moreira } \\
\text { R.C.R, } \\
\text { Barros } \\
\text { K.C.C, } \\
\text { Servo } \\
\text { M.L.S, } \\
\text { Bispo T.C.F. }\end{array}$ & $\begin{array}{l}\text { Compreender as práticas } \\
\text { de humanização no } \\
\text { transcurso parturitivo na } \\
\text { ótica de puérperas e } \\
\text { enfermeiras obstétricas. }\end{array}$ & $\begin{array}{l}\text { Pesquisa exploratória, } \\
\text { descritiva, qualitativa, } \\
\text { desenvolvida em uma } \\
\text { maternidade no estado da } \\
\text { Bahia. }\end{array}$ & $\begin{array}{l}\text { Verificou-se que os enfermeiros } \\
\text { obstetras estão qualificados para a } \\
\text { assistência à mulher em trabalho } \\
\text { de parto e nascimento }\end{array}$ & 2021 \\
\hline 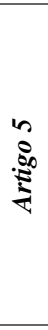 & $\begin{array}{l}\text { Conhecimento } \text { de } \\
\text { puérperas sobre boas } \\
\text { práticas em centro de } \\
\text { parto. }\end{array}$ & $\begin{array}{l}\text { Silva E.A.; } \\
\text { Pereira } \\
\text { A.M.M.; } \\
\text { Dantas } \\
\text { S.L.C.; } \\
\text { Soares } \\
\text { P.R.A.L.; } \\
\text { Melo L.P.T.; } \\
\text { Costa N. et } \\
\text { al. }\end{array}$ & $\begin{array}{l}\text { Analisar o conhecimento } \\
\text { das puérperas acerca das } \\
\text { boas práticas realizadas por } \\
\text { enfermeiros na assistência } \\
\text { ao parto e nascimento. }\end{array}$ & $\begin{array}{l}\text { Trata-se de um estudo } \\
\text { transversal desenvolvido } \\
\text { no centro de parto normal e } \\
\text { alojamento conjunto de um } \\
\text { hospital municipal. }\end{array}$ & $\begin{array}{l}\text { Verifica-se a necessidade de se } \\
\text { intensificar as ações durante a } \\
\text { assistência pré-natal na } \\
\text { perspectiva de se conceder } \\
\text { autonomia a mulher para o } \\
\text { trabalho de parto e parto. }\end{array}$ & 2021 \\
\hline$\frac{1}{10}$ & $\begin{array}{l}\text { Barreiras à } \\
\text { implementação das } \\
\text { Diretrizes Nacionais de } \\
\text { Assistência ao Parto } \\
\text { Normal: uma análise } \\
\text { prototípica das } \\
\text { representações sociais de } \\
\text { atores estratégicos. }\end{array}$ & $\begin{array}{lr}\text { Vidal Á.T, } \\
\text { Comes Y, } \\
\text { Barreto J.O, } \\
\text { Rattner D. }\end{array}$ & $\begin{array}{l}\text { Analisar as representações } \\
\text { sociais de atores } \\
\text { estratégicos envolvidos na } \\
\text { assistência ou gestão em } \\
\text { saúde, sobre as questões } \\
\text { que envolvem a mulher, o } \\
\text { parto e o nascimento. }\end{array}$ & $\begin{array}{l}\text { Estudo qualitativo } \\
\text { descritivo, de coorte } \\
\text { transversal, baseado num } \\
\text { teste de associação livre de } \\
\text { palavras, com } 12 \text { atores } \\
\text { estratégicos. }\end{array}$ & $\begin{array}{l}\text { Observou-se elementos } \\
\text { facilitadores para a construção de } \\
\text { caminhos possíveis para o } \\
\text { enfrentamento de barreiras e } \\
\text { crenças relacionadas ao parto e ao } \\
\text { medo da dor, atuando como } \\
\text { representações justificadoras de } \\
\text { intervenções desnecessárias no } \\
\text { corpo feminino. }\end{array}$ & 2021 \\
\hline 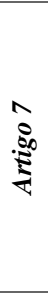 & $\begin{array}{l}\text { Uso de métodos não } \\
\text { farmacológicos durante } \\
\text { o trabalho de parto. }\end{array}$ & $\begin{array}{l}\text { Maffei } \\
\text { M.C.V, Zani } \\
\text { A.V, } \\
\text { Bernardy } \\
\text { C.C.F, Sodré } \\
\text { T.M, Pinto } \\
\text { K.R.T.F. }\end{array}$ & 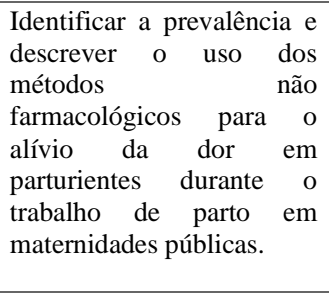 & $\begin{array}{l}\text { Trata-se de um estudo } \\
\text { quantitativo, descritivo, } \\
\text { transversal, realizado com } \\
344 \text { parturientes, por meio } \\
\text { da análise de prontuários. } \\
\text { Realizou-se a análise } \\
\text { descritiva com frequências } \\
\text { absolutas e relativas. }\end{array}$ & $\begin{array}{l}\text { Conclui-se todas as parturientes } \\
\text { devem receber cuidados } \\
\text { referentes aos métodos não } \\
\text { farmacológicos para o alívio da } \\
\text { dor durante o trabalho de parto, } \\
\text { pois é uma ação baseada em } \\
\text { evidências e incorporada como } \\
\text { uma das estratégias prioritárias de } \\
\text { assistência às parturientes. }\end{array}$ & 2020 \\
\hline
\end{tabular}




\begin{tabular}{|c|c|c|c|c|c|c|}
\hline$\underbrace{\infty}_{\substack{1 \\
\infty}}$ & $\begin{array}{l}\text { Percepção das } \\
\text { enfermeiras obstétricas } \\
\text { na assistência ao parto: } \\
\text { resgate da autonomia e } \\
\text { empoderamento da } \\
\text { mulher. }\end{array}$ & $\begin{array}{l}\text { Duarte M.R, } \\
\text { Alves V.H, } \\
\text { Rodrigues } \\
\text { D.P, } \\
\text { Marchiori } \\
\text { G.R.S, } \\
\text { Guerra } \\
\text { J.V.V, } \\
\text { Pimentel } \\
\text { M.M. }\end{array}$ & $\begin{array}{l}\text { Compreender } \\
\text { a percepção das enfermeira } \\
\text { s obstétricas sobre } \\
\text { a assistência r de } \\
\text { enfermagem no Centro } \\
\text { de Parto Normal. }\end{array}$ & $\begin{array}{l}\text { Estudo descritivo, } \\
\text { exploratório, de abordagem } \\
\text { qualitativa, } \\
\text { realizado entrevista semiest } \\
\text { ruturada com dezoito } \\
\text { Enfermeiras obstétricas } \\
\text { no Centro de Parto } \\
\text { Normal do Hospital da Mul } \\
\text { her Mariska Ribeiro, e } \\
\text { submetidas a análise de } \\
\text { conteúdo na modalidade } \\
\text { temática. }\end{array}$ & $\begin{array}{l}\text { Conclui-se que a valoração das } \\
\text { práticas humanizadas no contexto } \\
\text { do parto e } \\
\text { nascimento é integrante da } \\
\text { atuação da enfermeira obstétrica, } \\
\text { e tem a possibilidade de repensar } \\
\text { o modelo de atenção a mulher } \\
\text { no parto e nascimento, com } \\
\text { ruptura e engajamento } \\
\text { político, social e econômico } \\
\text { da humanização. }\end{array}$ & 2020 \\
\hline 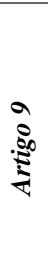 & $\begin{array}{l}\text { Ações de acompanhantes } \\
\text { durante o parto: } \\
\text { compreensão a partir da } \\
\text { fenomenologia social. }\end{array}$ & $\begin{array}{l}\text { Messa, Iris } \\
\text { Elisabete } \\
\text { Gomes et al. }\end{array}$ & $\begin{array}{l}\text { Compreender } r a \\
\text { intencionalidade das ações } \\
\text { dos acompanhantes de } \\
\text { mulheres em processo } \\
\text { parturitivo. }\end{array}$ & $\begin{array}{l}\text { Pesquisa qualitativa, } \\
\text { fenomenológica, } \\
\text { desenvolvida em uma } \\
\text { unidade de alojamento } \\
\text { conjunto em hospital } \\
\text { universitário no Sul do } \\
\text { Brasil. }\end{array}$ & $\begin{array}{l}\text { O estudo demonstra que é } \\
\text { necessário discutir e difundir as } \\
\text { boas práticas de atenção ao parto } \\
\text { e nascimento e desenvolver ações } \\
\text { educativas para que } \\
\text { compreendam suas contribuições } \\
\text { no processo de parturição e seu } \\
\text { papel social. }\end{array}$ & 2020 \\
\hline$\frac{\sqrt{1}}{\infty}$ & $\begin{array}{l}\text { Percepções das gestantes } \\
\text { quanto à escolha da via } \\
\text { de parto. }\end{array}$ & $\begin{array}{l}\text { Spigolon } \\
\text { D.N, Teston } \\
\text { E.F, Maran } \\
\text { E, Varela } \\
\text { P.R.L, } \\
\text { Biazyan S.F, } \\
\text { Ribeiro } \\
\text { B.M.S. }\end{array}$ & $\begin{array}{l}\text { Conhecer as percepções } \\
\text { das gestantes quanto à } \\
\text { escolha da via de parto. }\end{array}$ & $\begin{array}{l}\text { Trata-se de um estudo } \\
\text { descritivo com abordagem } \\
\text { qualitativa, realizado com } \\
\text { gestantes de um município } \\
\text { da região noroeste do } \\
\text { Estado do Paraná. }\end{array}$ & $\begin{array}{l}\text { Sugerem-se ações educativas } \\
\text { esclarecedoras para diminuir } \\
\text { inseguranças nas decisões das } \\
\text { gestantes e possibilitar autonomia } \\
\text { na escolha consciente quanto à } \\
\text { via de parto. }\end{array}$ & 2020 \\
\hline$\frac{\sqrt{1}}{\infty}$ & $\begin{array}{l}\text { O plano individual de } \\
\text { parto como estratégia de } \\
\text { ensino-aprendizagem } \\
\text { das boas práticas de } \\
\text { atenção obstétrica. }\end{array}$ & $\begin{array}{l}\text { Narchi, } \\
\text { Nádia Zanon } \\
\text { et al. }\end{array}$ & $\begin{array}{l}\text { Verificar o conhecimento } \\
\text { de estudantes sobre o plano } \\
\text { individual de parto e } \\
\text { conhecer sua opinião a } \\
\text { respeito da utilização dessa } \\
\text { estratégia de ensino- } \\
\text { aprendizagem e das boas } \\
\text { práticas obstétricas. }\end{array}$ & $\begin{array}{l}\text { Estudo descritivo, com } \\
\text { alunos de Obstetrícia que } \\
\text { cursavam estágios na } \\
\text { atenção básica. }\end{array}$ & $\begin{array}{l}\text { Além de conhecerem o plano de } \\
\text { parto e aplicá-lo, os estudantes o } \\
\text { consideram muito relevante para } \\
\text { o ensino e a aprendizagem das } \\
\text { boas práticas obstétricas. }\end{array}$ & 2019 \\
\hline 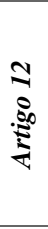 & $\begin{array}{lr}\begin{array}{l}\text { Percepção } \\
\text { enfermeiros }\end{array} & \text { dos } \\
\text { diante do } & \text { parto } \\
\text { humanizado. } & \end{array}$ & $\begin{array}{l}\text { Vilela A.T, } \\
\text { Tenório D.S, } \\
\text { Silva R.M.S, } \\
\text { Silva J.C.B } \\
\text { da, } \\
\text { Albuquerque } \\
\text { N.L.A. }\end{array}$ & $\begin{array}{l}\text { Desvelar a percepção dos } \\
\text { enfermeiros obstetras sobre } \\
\text { o parto humanizado. }\end{array}$ & $\begin{array}{l}\text { Trata-se de um estudo } \\
\text { qualitativo, descritivo e } \\
\text { exploratório desenvolvido } \\
\text { em uma maternidade. }\end{array}$ & $\begin{array}{l}\text { Concluiu-se que haja uma melhor } \\
\text { preparação de todos os processos } \\
\text { de educação continuada. }\end{array}$ & 2019 \\
\hline$\sum_{\substack{\infty \\
\infty}}^{\infty}$ & $\begin{array}{l}\text { Perfil sociodemográfico, } \\
\text { epidemiológico e } \\
\text { obstétrico de parturientes } \\
\text { em um hospital e } \\
\text { maternidade de Sobral, } \\
\text { Ceará. }\end{array}$ & $\begin{array}{l}\text { Andrade } \\
\text { S.G, } \\
\text { Vasconcelos } \\
\text { Y.A, } \\
\text { Carneiro } \\
\text { A.R.S, } \\
\text { Severiano } \\
\text { A.R.G, } \\
\text { Terceiro } \\
\text { A.J.M.D, } \\
\text { Silva T.B, et } \\
\text { al. } \\
\end{array}$ & $\begin{array}{l}\text { Identificar o perfil } \\
\text { sociodemográfico, } \\
\text { epidemiológico } \\
\text { obstétrico de parturientes } \\
\text { atendidas em hospital } \\
\text { maternidade na cidade de } \\
\text { Sobral, Ceará. }\end{array}$ & $\begin{array}{lr}\text { Estudo } & \text { descritivo, } \\
\text { documental } & \text { utilizando } \\
\text { como fonte de dados } \\
\text { prontuários de parturientes. }\end{array}$ & $\begin{array}{l}\text { Contribuir com a melhoria na } \\
\text { qualidade da assistência prestada, } \\
\text { uma vez que é de suma } \\
\text { importância } \\
\text { profissionais/agentes de de saúde } \\
\text { conheçam o perfil sócio } \\
\text { obstétrico das parturientes que } \\
\text { são atendidas nas maternidades. }\end{array}$ & 2018 \\
\hline$\frac{\sqrt{1}}{2}$ & $\begin{array}{l}\begin{array}{l}\text { Assistência } \\
\text { enfermagem no parto } \\
\text { humanizado }\end{array} \\
\text { num }\end{array}$ & $\begin{array}{l}\text { Nascimento } \\
\text { F.C.V, Silva } \\
\text { M.P, Viana } \\
\text { M.R.P. }\end{array}$ & $\begin{array}{l}\text { Analisar na literatura } \\
\text { cientifica a importância da } \\
\text { assistência de enfermagem } \\
\text { no parto humanizado, } \\
\text { destacando a importância } \\
\text { deste profissional no } \\
\text { momento do parto. }\end{array}$ & $\begin{array}{l}\text { Trata-se de uma revisão } \\
\text { integrativa de literatura. }\end{array}$ & $\begin{array}{l}\text { Aponta-se ainda muitas } \\
\text { dificuldades como a necessidade } \\
\text { de capacitação profissional e a } \\
\text { falta de estrutura física. }\end{array}$ & 2018 \\
\hline$\underbrace{\infty}_{\substack{n \\
\infty}}$ & $\begin{array}{l}\text { Sistematização da } \\
\text { Assistência de } \\
\text { Enfermagem em unidade } \\
\text { básica de saúde: } \\
\text { percepção da equipe de } \\
\text { enfermagem. }\end{array}$ & $\begin{array}{l}\text { Ribeiro G.C, } \\
\text { Padoveze } \\
\text { M.C. }\end{array}$ & $\begin{array}{lr}\text { Realizar um diagnóstico } \\
\text { situacional } \\
\text { Sistematização } & \text { da } \\
\text { Assistência } & \text { da } \\
\text { Enfermagem. } \\
\text { (SAE) em uma Unidade } \\
\text { Básica de Saúde na } \\
\text { percepção da equipe de } \\
\text { enfermagem. }\end{array}$ & $\begin{array}{l}\text { Estudo quantitativo, } \\
\text { descritivo-exploratório, } \\
\text { realizado em uma Unidade } \\
\text { Básica de Saúde do } \\
\text { município de São Paulo. }\end{array}$ & $\begin{array}{l}\text { Sugere contribuir para a efetiva } \\
\text { implantação da SAE nesta } \\
\text { unidade e apontar diretrizes em } \\
\text { outros contextos semelhantes. }\end{array}$ & 2018 \\
\hline
\end{tabular}




\begin{tabular}{|c|c|c|c|c|c|c|}
\hline 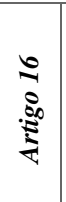 & $\begin{array}{l}\text { Avaliação da satisfação } \\
\text { de puérperas em relação } \\
\text { ao parto. }\end{array}$ & $\begin{array}{l}\text { Riegert I.T, } \\
\text { Correia } \\
\text { M.B, } \\
\text { Andrade } \\
\text { Â.R.L de et } \\
\text { al. }\end{array}$ & $\begin{array}{l}\text { Analisar a satisfação } \\
\text { acerca do trabalho de parto } \\
\text { e parto de mulheres que } \\
\text { pariram em uma } \\
\text { maternidade de alto risco. }\end{array}$ & $\begin{array}{l}\text { Trata-se de estudo } \\
\text { quantitativo, transversal, } \\
\text { com 91 puérperas, } \\
\text { realizado em um hospital } \\
\text { de alta complexidade. }\end{array}$ & $\begin{array}{ll}\text { Sugere-se mais investigação } \\
\text { sobre essa temática a fim de } \\
\text { identificar as determinantes } & \text { da } \\
\text { satisfação, bem como de } & \text { dem } \\
\text { reorganização da política de } & \text { assistência obstétrica. }\end{array}$ & 2018 \\
\hline 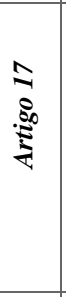 & $\begin{array}{l}\text { Processo } r \text { de } \\
\text { Enfermagem em centro } \\
\text { obstétrico: perspectiva } \\
\text { dos enfermeiros. }\end{array}$ & $\begin{array}{lr}\text { Fraga } & \text { T.F, } \\
\text { Matos } & \text { E, } \\
\text { Costa } & \text { R, } \\
\text { Salum } & \text { N.C, } \\
\text { Maliska } & \\
\text { I.C.A. }\end{array}$ & $\begin{array}{l}\text { Apreender a percepção de } \\
\text { enfermeiros sobre o PE e o } \\
\text { modelo de histórico de } \\
\text { enfermagem realizado com } \\
\text { a gestante/parturiente no } \\
\text { centro obstétrico de um } \\
\text { hospital do sul do Brasil. }\end{array}$ & $\begin{array}{lr}\text { Estudo exploratório, } \\
\text { descritivo com abordagem } \\
\text { qualitativa, do qual } \\
\text { participaram reze } \\
\text { enfermeiros que atuam em } \\
\text { Emergência Obstétrica ou } \\
\text { Centro Obstétrico. }\end{array}$ & $\begin{array}{l}\text { Verificou-se que os enfermeiros } \\
\text { estão qualificados para a } \\
\text { assistência e compreendem que a } \\
\text { qualidade do PE alcançará } \\
\text { melhorias a partir de uma nova } \\
\text { proposta de histórico, e que os } \\
\text { diagnósticos de enfermagem, } \\
\text { instrumentalizam e orientam o } \\
\text { processo de cuidar. }\end{array}$ & 2018 \\
\hline$\stackrel{\substack{i \\
\infty}}{\infty}$ & $\begin{array}{l}\text { Contribuições da } \\
\text { enfermagem obstétrica } \\
\text { para uma assistência } \\
\text { segura e de qualidade em } \\
\text { um hospital público } \\
\text { alagoano: um relato de } \\
\text { experiência }\end{array}$ & $\begin{array}{l}\text { Costa, } \\
\text { R.L.M. }\end{array}$ & $\begin{array}{l}\text { Descrever as contribuições } \\
\text { da enfermagem obstétrica } \\
\text { para uma assistência } \\
\text { segura e de qualidade em } \\
\text { um hospital público } \\
\text { alagoano. }\end{array}$ & $\begin{array}{l}\text { Estudo descritivo, relato } \\
\text { de experiência, ocorrido no } \\
\text { período de fev/2015 a } \\
\text { out/2016, no Centro } \\
\text { Obstétrico Doutor Ulisses } \\
\text { Pereira do Hospital Nossa } \\
\text { Senhora do Bom Conselho, } \\
\text { situado no município de } \\
\text { Arapiraca-AL. }\end{array}$ & $\begin{array}{l}\text { Verificou-se que os enfermeiros } \\
\text { demonstram conhecimento } \\
\text { técnico e científico adequado para } \\
\text { a assistência. }\end{array}$ & 2017 \\
\hline 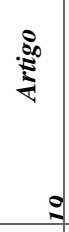 & $\begin{array}{lr}\text { Práticas } & \text { dos } \\
\text { profissionais } & \text { de } \\
\text { enfermagem diante } & \text { do } \\
\text { parto humanizado. } & \end{array}$ & $\begin{array}{l}\text { Andrade, } \\
\text { L.O. Felix } \\
\text { E.S.P, Souza } \\
\text { F.S, Gomes } \\
\text { L.O.S, } \\
\text { Boery } \\
\text { R.N.S.O } \\
\end{array}$ & $\begin{array}{l}\text { Conhecer como são } \\
\text { desenvolvidas as práticas } \\
\text { de humanização durante o } \\
\text { trabalho de parto. }\end{array}$ & 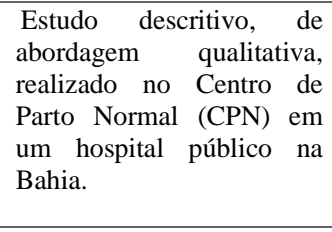 & $\begin{array}{l}\text { Verificou-se que se torna de suma } \\
\text { importância o preparo da } \\
\text { parturiente para o parto } \\
\text { humanizado desde o pré-natal, } \\
\text { com o emprego das práticas } \\
\text { humanizadas e respaldado nas } \\
\text { evidências científicas. }\end{array}$ & 2017 \\
\hline 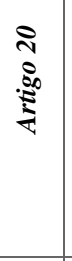 & $\begin{array}{l}\text { Abordagem da equipe } \\
\text { de enfermagem acerca } \\
\text { do parto humanizado no } \\
\text { pré-natal: uma visão } \\
\text { narrativa. }\end{array}$ & $\begin{array}{l}\text { Ragagnin } \\
\text { M.V, } \\
\text { Marchiori } \\
\text { M.R.C.T, } \\
\text { Diaz C.M.G, } \\
\text { Nicolli T, } \\
\text { Pereira S.B, } \\
\text { Silva L.D. } \\
\end{array}$ & $\begin{array}{l}\text { Identificar nas publicações } \\
\text { da literatura científica as } \\
\text { contribuições } \\
\text { desenvolvidas pela equipe } \\
\text { de enfermagem acerca das } \\
\text { abordagens quanto ao parto } \\
\text { humanizado durante as } \\
\text { consultas no pré-natal. }\end{array}$ & 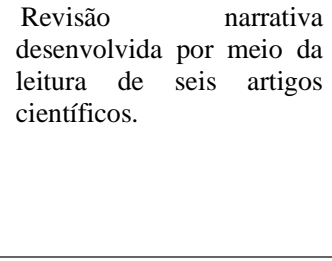 & $\begin{array}{l}\text { Os profissionais de enfermagem } \\
\text { devem assumir a postura de } \\
\text { educadores, } \\
\text { desenvolver na mulher sua } \\
\text { autoconfiança para viver a } \\
\text { gestação, o parto e o puerpério } \\
\text { positivamente. }\end{array}$ & 2017 \\
\hline$\stackrel{8}{8}$ & $\begin{array}{l}\text { Morbidade materna } \\
\text { grave identificada no } \\
\text { Sistema de Informações } \\
\text { Hospitalares do Sistema } \\
\text { Único de Saúde, no } \\
\text { estado do Paraná, 2010. }\end{array}$ & $\begin{array}{l}\text { Silva T.C.; } \\
\text { Varela } \\
\text { P.L.R.; } \\
\text { Oliveira } \\
\text { R.R.; } \\
\text { Mathias } \\
\text { T.A.F. }\end{array}$ & $\begin{array}{l}\text { Descrever a morbidade } \\
\text { materna grave }- \text { near miss } \\
\text { - entre mulheres residentes } \\
\text { no estado do Paraná, } \\
\text { Brasil, em 2010. }\end{array}$ & $\begin{array}{lr}\text { Estudo descritivo com } \\
\text { dados do } & \text { (SIH/SUS), com } \\
\text { registro de procedimentos } \\
\text { obstétricos } & \text { indicativos } \\
\text { de near miss. } & \end{array}$ & $\begin{array}{l}\text { Intensificar maior atenção às } \\
\text { mulheres com idades a partir de } \\
35 \text { anos, pois apresentaram } \\
\text { maiores taxas de morbidade } \\
\text { materna grave. }\end{array}$ & 2016 \\
\hline 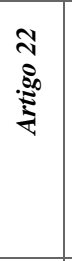 & $\begin{array}{lr}\text { Adequação } & \text { da } \\
\text { assistência } & \text { pré-natal } \\
\text { segundo } & \text { as } \\
\text { características } & \text { maternas } \\
\text { no Brasil } & \end{array}$ & $\begin{array}{l}\text { Domingues } \\
\text { R.M.S.M, } \\
\text { Viellas E.F, } \\
\text { Dias M.A.B, } \\
\text { Torres J.A, } \\
\text { Theme-Filha } \\
\text { M.M, Gama } \\
\text { S.G.N, et al. }\end{array}$ & $\begin{array}{llr}\text { Verificar o grau } & \text { de } \\
\text { adequação da } & \text { assistência } \\
\text { pré-natal no } & \text { Brasil e } & \text { sua } \\
\text { associação } & & \text { com } \\
\text { características } & & \\
\text { sociodemográficas } & \text { das } \\
\text { mulheres. } & \end{array}$ & $\begin{array}{l}\text { Trata-se de um estudo } \\
\text { descritivo, exploratório, } \\
\text { qualitativo. }\end{array}$ & $\begin{array}{l}\text { Sugere-se } \\
\text { estratégias voltadas para as } \\
\text { populações menos favorecidas } \\
\text { socialmente, visando facilitar o } \\
\text { ingresso precoce no pré-natal e o } \\
\text { contato com os serviços de saúde } \\
\text { para garantir a realização de } \\
\text { cuidados efetivos em saúde. }\end{array}$ & 2015 \\
\hline 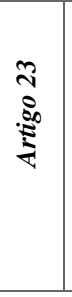 & $\begin{array}{l}\text { Fatores que influenciam } \\
\text { a gestante na escolha do } \\
\text { tipo de parto. }\end{array}$ & $\begin{array}{l}\text { Santana F.A; } \\
\text { Lahm J.V.; } \\
\text { Santos R.P. }\end{array}$ & $\begin{array}{l}\text { Investigar a percepção das } \\
\text { gestantes em relação aos } \\
\text { tipos de parto e orientações } \\
\text { que as mesmas receberam } \\
\text { durante o pré-natal. }\end{array}$ & $\begin{array}{l}\text { Pesquisa se caracterizou } \\
\text { por ser do tipo quali- } \\
\text { quantitativo, descritivo e } \\
\text { exploratório. A população } \\
\text { foi composta por 15 } \\
\text { gestantes que realizavam a } \\
\text { assistência pré-natal em } \\
\text { duas UBS de uma cidade } \\
\text { do oeste do Paraná. }\end{array}$ & $\begin{array}{l}\text { Considera-se, que o déficit de } \\
\text { conhecimento, a falta de } \\
\text { informações consistentes são } \\
\text { fatores determinantes perante o } \\
\text { processo de tomada de decisão } \\
\text { sobre a escolha do tipo de parto. }\end{array}$ & 2015 \\
\hline
\end{tabular}

Fonte: Dados da pesquisa.

Dos 23 artigos selecionados, em 09 (39,13\%) deles analisou-se a importância em preparar a mulher desde o início da gestação dando autonomia, utilizando boas práticas humanizadas com respaldo em evidências científicas. Além disso, 03 $(13,04 \%)$ tinham o objetivo de avaliar o conhecimento dos enfermeiros técnico e científico adequado para a assistência. No que se refere a vincular conhecimento, melhorar a qualidade da assistência humanizada pela equipe de enfermagem incluindo a 
mulher foi encontrado em 05 (21,73\%). Por fim, como sugestão de educação continuada para toda equipe de enfermagem e capacitação profissional foi encontrado em $06(26,08 \%)$.

\section{Discussão}

Após a análise de todos os artigos foram encontrados os seguintes temas, para discussão: Humanização do cuidado com as puérperas; O papel do enfermeiro com a equipe multiprofissional e Métodos não farmacológicos durante o parto humanizado.

\subsection{Humanização do cuidado com as puérperas}

A humanização é definida como o conjunto de práticas que incluem respeito ao processo fisiológico e a dinâmica de cada nascimento, no qual as instituições devem ser cuidadosas, evitar os excessos e utilizar criteriosamente os recursos disponíveis. Esse modelo de assistência ao parto é defendido por diversas organizações e movimentos, que observam que o bem-estar físico e emocional da mulher favorecendo a redução dos riscos e das complicações no parto (Almeida et al, 2021).

Uma das finalidades da atuação da enfermagem no centro obstétrico é humanizar o cuidado, proporcionar um ambiente calmo com isso reduzir a ansiedade e o medo nas mulheres em trabalho de parto, além de ofertar técnicas para o alívio da dor, pois o que motiva várias mulheres a sentirem medo do parto normal, são os relatos do uso de intervenções que muitas vezes são desnecessárias, como: episiotomia, acesso venoso, jejum muito prolongado (se o trabalho de parto for longo a mulher sente-se muito fraca), a manobra de Kristeller também assusta muito as mulheres em geral, e o uso de medicação que induzem o trabalho de parto podendo causar exaustão, dentre outras (Vidal et al, 2021). Somando o medo de tudo que foi citado, a cesariana aparece como acalento, esse cenário pode continuar influenciando as mulheres na escolha por parto cesariano (Andrade et al, 2018).

Deste modo, observou-se que no serviço em geral há um aumento significativo de partos cesáreos, e que as informações prestadas no pré-natal são insuficientes, e ainda que mesmo que as gestantes sejam orientadas a optarem pelo parto vaginal, os desfechos são, em sua maioria cesáreas sem indicações legítimas para tal (Santana, Lahm, \& Santos, 2015) (Silva et al, 2021).

A assistência humanizada prestada pela equipe de enfermagem encontra dificuldades, pois as ações da equipe de enfermagem são, muitas vezes, voltadas apenas para o procedimento em si e não para a mulher, limitando-se apenas à prescrição médica para prestar assistência à parturiente, deixando de lado à implantação da Sistematização da Assistência de Enfermagem (SAE) (Fraga et al, 2018) (Vidal et al, 2021). Além disso, no dia-a-dia do enfermeiro, existe o excesso de atividades burocráticas voltadas para o controle de material, gerenciamento do pessoal de enfermagem, registros e relatórios escritos de forma não sistematizada, caracterizando a execução de tarefas rotineiras, e revelando, assim, a falta de disponibilidade com assistência (Domingues et al, 2015) (Nascimento et al, 2018).

Outro estudo traz que muitos fatores dificultam a assistência de enfermagem, como questões relacionadas à infraestrutura, déficit de pessoal, sobrecarga de trabalho, falta de apoio da chefia e gestores, falta de recursos materiais, entre outros (Domingues et al, 2015).

Como forma de organizar o cuidado e gerir o tempo, o estudo propõe implementar a sistematização da assistência de enfermagem (SAE) (Ribeiro, \& Padoveze, 2018). Desta forma, o enfermeiro deixará de se basear apenas na prescrição médica para realizar seus cuidados e começará a utilizar seu senso crítico para o planejamento da assistência evidenciando sua autonomia e favorecendo o reconhecimento profissional pelos membros da equipe (Fraga et al, 2018) (Vidal et al, 2021). Tendo isso em vista, constata-se que a equipe de enfermagem é fundamental na implementação e execução das práticas de humanização ao parto e nascimento. Porém existem fatores agravantes dessas ações (Vidal et al, 2021). 


\subsection{O papel do enfermeiro na participação do período parturitivo}

O enfermeiro obstetra deve desenvolver práticas de educação em saúde pautados nas ciências sociais, no conhecimento científico e popular, e também, valorizar a humanização do cuidado à mulher durante todo o processo de parir (Silva et al, 2010). Dessa forma, a relação entre a mulher e o enfermeiro deverá ser um local aberto para esclarecimento de dúvidas, possibilitando o desenvolvimento de ações educativas, onde o cuidar é o principal fundamento dos profissionais da enfermagem (Spigolon et al, 2020). Sendo assim, terá a possibilidade em amenizar a insegurança e os medos da mulher, promovendo um ambiente saudável, tranquilo e sem traumas (Almeida et al, 2021).

$\mathrm{O}$ enfermeiro participa da equipe multiprofissional e desempenha importante papel no cuidado prestado à gestante. Por meio do Processo de Enfermagem (PE) o enfermeiro integraliza a assistência de enfermagem à parturiente, planejando $\mathrm{e}$ promovendo um cuidado específico conforme suas necessidades (Silva et al, 2021). A enfermagem tem a oportunidade de criar vínculo com a parturiente e promover um cuidado diferenciado e efetivo à mesma, através de uma assistência qualificada, acolhedora e humanizada iniciando desde o pré-natal (Andrade et al, 2017).

Em um estudo realizado em Alagoas foram constatados os cuidados prestados pela equipe de enfermagem no centro obstétrico, tais como o acolhimento na chegada da paciente no setor, sendo que, nos cuidados obstétricos prestados, a equipe de enfermagem explicava todos os procedimentos e suas finalidades, enfatizando a importância de uma participação mais ativa no processo de parir e nascer (Costa, \& Dalla, 2021).

\subsection{Métodos não farmacológicos durante o parto humanizado}

Foram observados, cuidados, como a oferta de métodos não farmacológicos de alívio à dor no trabalho de parto, os quais tiveram uma boa aceitação pelas parturientes e compreenderam medidas de conforto e apoio, tais como: massagens relaxantes, banhos mornos de aspersão, exercícios com a bola suíça, incentivo à manutenção deposições verticais, ou seja, a deambulação e permanência na posição de cócoras, por períodos suportáveis pelas mulheres-parturientes (Costa, \& Dalla, 2021) (Maffei et al, 2020). Segundo Maffei (Maffei et al, 2020), a equipe de enfermagem tem um papel fundamental na realização dos cuidados não farmacológicos para alívio da dor, proporcionado à parturiente. Em consonância com a política de humanização, também foi ofertado o contato pele a pele imediato, o estímulo ao início precoce da amamentação, favorecendo o vínculo mãe-filho, respeitando-se sempre o desejo e as condições de saúde das puérperas e dos bebês, o estímulo à presença do acompanhante de escolha das mulheres durante o processo parturitivo (Costa, \& Dalla, 2021).

Em outro estudo os profissionais de enfermagem referiram que as práticas como uso do cavalinho, exercício com a bola, banho de chuveiro, escolha da posição para parir, diálogo, deambulação e massagem de alívio fazem parte de uma assistência humanizada presente no serviço em questão (Almeida et al, 2021) (Narchi, 2019).

\section{Considerações Finais}

Este estudo possibilitou a evidência da atuação da enfermagem na promoção do parto humanizado. Foram constatados vários cuidados que podem ser colocados em prática para contribuir com esse modelo de assistência, tais como acolhimento, criação de vínculo, oferta de métodos não farmacológicos para alívio da dor, contato pele a pele, estímulo a amamentação precoce, dentre outros.

Chama atenção de que, não há dúvidas, se a gestante realizar a quantidade de consultas recomendadas pelo MS influenciará diretamente na qualidade da atenção pré-natal, portanto, é de extrema importância à conscientização dessas parturientes na realização do pré-natal corretamente, para assim, evitar maiores riscos de mortalidade neonatal e materna.

É preocupante a elevada prevalência de cesariana encontrada nos estudos comparado a literatura, deixando explícita a necessidade de um olhar crítico dos gestores e dos profissionais de saúde para entrar com intervenção de forma eficaz, e assim 
diminuir o percentual de cesáreas no país. Para isso, é importante reforçar as vantagens do parto vaginal, com assistência humanizada, dando autonomia a parturiente.

Diante disso, conclui-se que a enfermagem é essencial na consolidação do modelo de assistência humanizado. Porém ainda é preciso superar alguns desafios, tais como o dimensionamento de pessoal e sobrecarga de trabalho, pois os estudos evidenciam que a qualidade da assistência de enfermagem fica comprometida devido à falta de profissionais e excesso de atividades burocráticas. Como forma de organização do cuidado, sugere-se a implementação da SAE, assim, o enfermeiro poderá gerir melhor o tempo e prestar uma assistência com autonomia e cientificidade.

Como sugestão para futuros trabalhos, é dada a importância de abordar o Cenário e Condições de Trabalho da equipe de Enfermagem para que haja um atendimento humanizado. Tendo em vista que para excelência de um bom cuidado seja primordial um cenário e condições que beneficiem sua prática.

\section{Referências}

Bomfim, A. N. A., Couto, T. M., Lima, K. T. R. dos S., Almeida, L. T. da S., Santo, G. de O., \& Santana, A. T. de. (2021). Percepções de mulheres sobre a assistência de enfermagem durante o parto normal. Revista Baiana De Enfermagem35 ,. https://doi.org/10.18471/rbe.v35.39087.

Costa, L. D., Warmling, K. M., Cero, T. D., Darlosoletta, K., Zonta, F. N. S., Trevisan, M. G., \& Cavalheiri, J. C. (2021). Adesão de profissionais às boas práticas obstétricas e intervenções realizadas com parturientes. Rev Rene. 2021;22:e61474. https://doi.org/10.15253/2175-6783.20212261474.

Spigolon, D. N., Teston, E. F., Maran, E., Varela, P. L. R., Biazyan, S. F., \& Ribeiro, B. M. S. S. (2020). Percepções das gestantes quanto à escolha da via de parto. Saúde e Pesquisa. https://doi.org/10.17765/2176-9206.2020v13n4p789-798.

Vidal, Á. T., Comes, Y., Barreto, J. O. M., Rattner, D. (2021). Barreiras à implementação das diretrizes nacionais de assistência ao parto normal: uma análise prototípica das representações sociais de atores estratégicos. Revista de Saúde Coletiva. https://doi.org/10.1590/S0103-73312021310110.

Silva, T. C., Varela, P. L. R., Oliveira, R. R., \& Mathias, T. A. F., (2010). Morbidade materna grave identificada no sistema de informações hospitalares do sistema único de saúde, no estado do Paraná, 2010. Epidemiologia e Serviços de Saúde. 25(3), 617-628. http://dx.doi.org/10.5123/S1679-49742016000300017.

Domingues, R. M. S. M., Viellas, E. F., Dias, M. A. B., Torres, J. A., Theme-Filha, M. M., Gama, S. G. N. da., \& Leal, M. C., (2015). Adequação da assistência pré-natal segundo as características maternas no Brasil. Rev Panam Salud Publica. 2015;37(3):140-7.

Almeida, A. I. S., Araújo, F., \& Luzia, C., (2021). Parir e nascer em casa: vivências de enfermeiras obstétricas na assistência ao parto domiciliar planejado. Enfermagem em Foco. 11(6),

Leal, M. S., Moreira, R. C. R., Barros, K. C. C., Servo, M. L. S., \& Bispo, T. C. F., (2021). Práticas de humanização no transcurso parturitivo na ótica de puérperas e enfermeiras obstétricas. Revista Brasileira de enfermagem. 74 (suppl 4). https://doi.org/10.1590/0034-7167-2019-0743.

Andrade, S. G., Vasconcelos, Y. A., Carneiro, A. R. S., Severiano, A. R. G., Terceiro, A. J. M. D., Silva, T. B., Carneiro, J. K. R., \& Oliveira, M. A. S., (2018). Perfil sociodemográfico, epidemiológico e obstétrico de parturientes em um hospital e maternidade de Sobral, Ceará. Revista Prevenção de Infecção e Saúde. (4):7283. https://doi.org/10.26694/repis.v4i0.7283.

Santana, F. A., Lahm J. V., \& Santos, R. P., (2015). Fatores que influenciam a gestante na escolha do tipo de parto. Revista da Faculdade de Ciências Médicas de Sorocaba. 17(3), $123-127$.

Silva, E. A., Pereira, A. M. M., Dantas, S. L. C., Soares, P. R. A. L., Melo, L. P. T., Costa, N., Gomes, A. M., \& Torres, J. D. M. (2015). Conhecimento de puérperas sobre boas práticas em centro de parto. Revista da Faculdade de Ciências Médicas de Sorocaba. 17(3), 123 - 127, https://doi.org/10.5205/19818963.2021.246029.

Fraga, T. F., Matos, E., Costa, R., Salum, N. C., \& Maliska, I. C. A. (2018). Processo de enfermagem em centro obstétrico: pespectiva dos enfermeiros. Texto e Contexto Enfermagem. 27 (3), 2018. https:/doi.org/10.1590/0104-070720180004600016.

Nascimento, F. C. V., Silva, M. P., \& Viana, M. R. P. (2018). Assistência de enfermagem no parto humanizado. Revista Prevenção de Infecção e Saúde. 4:6887.

Ribeiro, G. C., \& Padoveze, M. C. (2018). Sistematização da assistência de enfermagem em unidade básica de saúde: percepção da equipe de enfermagem. Revista Escola de Enfermagem USP. 52 - 2018.

Andrade, L. O., Felix, E. S. P., Souza, F. S., Gomes, L. O. S., \& Boery, R. N. S. O. (2017). Práticas dos profissionais de enfermagem diante do parto humanizado. Revista de Enfermagem UFPE on line. 11(Supl. 6):2576-85. https://10.5205/reuol.9799-86079-1-RV.1106sup201712.

Maffei, M. C. V., Zani, A. V., Bernardy, C. C. F., Sodré, T. M., \& Pinto, K. R. T. F. (2020). Uso de métodos não farmacológicos durante o trabalho de parto. Revista de Enfermagem UFPE on line. 2020;15:e245001. https://doi.org/10.5205/1981-8963.2021.245001.

Narchi, N. Z., Venâncio, K. C. M. P., Ferreira, F. M., \& Vieira, J. R. (2019). O plano individual de parto como estratégia de ensino-aprendizagem das boas práticas de atenção obstétrica. Revista Escola de Enfermagem USP. 53, e03518. 